\title{
FAST-forge of novel Ti-6Al-4V/Ti-6Al-2Sn-4Zr-2Mo bonded, near net shape forgings from surplus AM powder
}

Oliver Levano ${ }^{1}$, Nicholas Weston ${ }^{1}$, Jacob Pope ${ }^{1}$, Adam Tudball ${ }^{2}$, David Lunn ${ }^{3}$, Gavin Baxter ${ }^{4}$, Martin Jackson ${ }^{1}$

${ }^{1}$ Department of Materials Science and Engineering, The University of Sheffield, Sir Robert Hadfield building, Mappin St, Sheffield, S1 3JD, United Kingdom

${ }^{2}$ Kennametal Manufacturing (UK) Ltd, Lake Road, Leeway Industrial Estate, Newport, South Wales NP19 4SR, United Kingdom

${ }^{3}$ W.H. Tildesley, Clifford Works, Bow Street, Willenhall, WV13 2AN, United Kingdom

${ }^{4}$ Rolls-Royce plc, PO Box 31, Derby, DE24 8BJ, UK

\begin{abstract}
$\underline{\text { Abstract }}$
Titanium alloys are used extensively in the aerospace sector due to the good combination of high strength-to-weight ratio and corrosive resistance. Many aerospace components are exposed to extreme service stress states and temperatures, which in some applications could compromise the component's performance if a single titanium alloy is used. A potential solution to this issue could be the combination of dissimilar titanium alloys in subcomponent regions, achieved through consolidating powders via field assisted sintering technology (FAST-DB) and subsequent hot forging (FAST-forge). In this paper, near net shape titanium-titanium alloy demonstrator components are produced from oversized AM powders in just two hybrid solid-state steps; FAST-DB and hot forging.
\end{abstract}

\section{Introduction}

Titanium has a high specific strength combined with an excellent corrosion resistance which makes it a key material in the aerospace sector. However, some of the applications in which titanium is used can suffer from a combination of failure mechanisms during service. For example, some components may require high creep resistance in some regions and high fatigue resistance in others. Therefore, the ideal solution would be to have different alloys in the sub regions of the component. Nevertheless, there are two main challenges with this solution; the first one is to find a technique that can produce a reliable multi material component. The second one is to make sure that the component does not fail at the bond line between the dissimilar alloys.

Powder metallurgy is one way to create multi material components because during the layout, the powders can be placed in defined arrays. Recently, spark plasma sintering (SPS) also known as field assisted sintering technology (FAST) has been exploited to join titanium alloys. Guillon et al. [3] discusses the several advantages of FAST over HIP. For example, the operational mode and the control over the sintering process is simpler for FAST. Moreover, it is an alternative method to fully densify powder, it has high reproducibility and the moulds can be recycled after each run. Suarez et al. [4] pointed out that FAST can increase densification without coarsening the microstructure due to the high heating rates produced in the heating step.

He et al. [5] were some of the first authors to use the FAST process to bond titanium, specifically, bonded two solid blocks of titanium, as opposed to powder. The results of the mechanical test performed in the join showed that failure occurred in areas near the bond. A similar experiment was performed by Miriyev et al. [6] in which Ti-6Al-4V was bonded to AISI4330 steel. The bond between the two materials failed by brittle fracture due to the formation of titanium carbides. Vincente [7] used FAST to bond the titanium alloy CP-Ti grade 2 with Co-28Cr-6Mo and observed that the roughness of the interface is influenced by the hardness of the two materials. The effect of the temperature, pressure and time in the mechanical properties when joining pre-sintered billets of Ti-45Al-7Nb-0.3W was studied by Zhao et al. [8]. It was observed that at higher temperatures the material failed in the base material while at higher pressure the material failed at the bond interface. Martin et al. [9] used an innovative approach to bond two titanium alloys using FAST: The method consisted of bonding a Ti-6A-4V 3D structure made with by electron beam melting (EBM) to CP-Ti grade 2 powder. This method generated a fully consolidated component with $99.5 \%$ of density. Recently, Pope et al. [10] studied the integrity of the diffusion bond (DB) of dissimilar alloy powders such as Ti-5553, Ti-6Al-4V and CP-Ti grade 2 through FAST, termed FAST-DB. Such FAST bonds of dissimilar alloys displayed excellent mechanical integrity under tensile testing, with failure occurring in the base material of the lowest strength alloy, as opposed to the bond region.

The current challenge with FAST is to directly obtain microstructures and shapes required for aerospace applications without further processing. For example, Weston and Jackson [11] developed and proved the concept of FAST-forge which consists of combining a component made via FAST with a forging step in order to provide enhanced mechanical performance. This process enables near net shape component to be produced from powder in only two solid-state steps. The effectiveness of FAST-forge for the high strength alloy Ti-5553 was demonstrated by Calvert et al. [12] where the microstructure of the conventional (+40 stage) processing route was similar to the two step FAST-forge.

The aim of this paper is to demonstrate the FAST-forge processing route on dissimilar FAST-DB titanium alloy preforms of Ti-6Al-4V and Ti-6Al-2Sn-4Zr-2Mo. A schematic of the FAST-forge process for a FAST-DB component is shown in Figure 1.

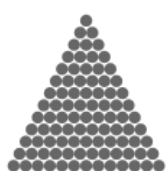

Alloy 1

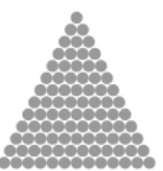

Alloy 2

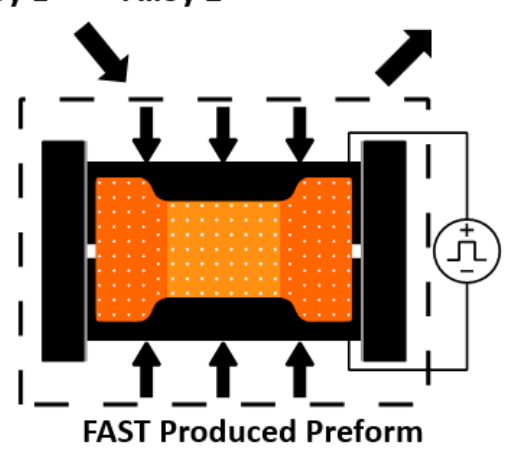

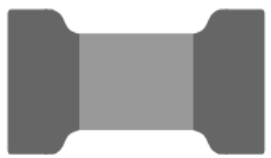

FAST-DB Preform

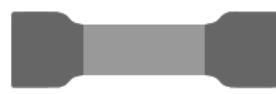

Near Net Shape

Component 


\section{Methodology}

\subsection{Powder feedstock}

The two titanium spherical powders used in this study are Ti-6Al-4V (Ti-64) produced by the plasma rotating electrode process (PREP) and Ti-6Al-2Sn-4Zr-2Mo (Ti6242 ) produced by the gas atomisation process (GA). The Ti-6242 was sourced from LPW Carpenter and the Ti-64 from ASM Starmet. The powder was surplus to requirements for additive manufacturing (AM) technologies. The particle size distribution (PSD) was measured under wet conditions with a Malvern Mastersizer 3000 laser particle size analyser. The PSD of the powder used is shown in Table 1 were the standard deviation is taken from a total of 20 measurements.

The powder's aspect ratio, roundness and porosity were also characterised using the optical microscope Olympus Bx51 with the software Clemex Vision PE image analysis system. The data showed that Ti-64 powder had higher roundness and less porosity than Ti-6242 powder.

Table 1. The table shows the PSD for the powders used in this paper.

\begin{tabular}{c|cccc}
\multicolumn{1}{c}{} & & $\boldsymbol{D x}(\mathbf{1 0})(\boldsymbol{\mu m})$ & $\boldsymbol{D x}(\mathbf{5 0})(\boldsymbol{\mu m})$ & Dx (90) $(\boldsymbol{\mu m})$ \\
\hline \multirow{2}{*}{$T i-64$} & Mean & 93.2 & 160 & 299 \\
& Std Dev & 1.11 & 1.71 & 3.7 \\
\hline \multirow{2}{*}{$T i-6242$} & Mean & 93.5 & 113 & 137 \\
& Std Dev & 0.30 & 0.17 & 0.63
\end{tabular}

\subsection{Processing of the FAST-DB Ti-64/Ti-6242 disks from powder}

The first step was to create a FAST-DB disk from the Ti-64 and Ti-6242 powder with defined bond lines. The FAST was carried out with an FCT Systeme GmbH Spark Plasma Sintering Furnace type H-HP D 250 located at Kennametal Manufacturing (UK) Ltd., Newport, shown in Figure 2 (a), which is capable of producing 250 mm diameter consolidated disks. With a view of creating dissimilar titanium alloy forging billets with defined bond lines, it was necessary to set up dividers inside the graphite mould, as shown in Figure 2 (b). Each box of the grid created with the dividers was filled with either Ti-64 or Ti6242 powder (NB: that the powders were never blended together in this study). Once, the mould was filled with powder, the dividers were removed carefully to keep a straight line in the interface (and Figure 2 (c) still retains the grid pattern). Finally, after inserting the graphite paper and the top punch in the mould, the graphite mould is placed in the FAST furnace. The processing temperature below the $\beta$ trans with a dwell and pressure.

In Figure 2 (d) a schematic of the FAST furnace arrangement applied to fully consolidate the powder is shown. The sintering mechanism is accelerated through the application of a pulsed electrical current to heat the powder in combination with uniaxial mechanical pressure. All this process is done in a vacuum chamber to avoid oxidation of the powder and the temperature is controlled by a pyrometer situated very close to the sample. In the case of metal powders, such as titanium and nickel superalloys, the latter stages of the FAST process cycle are very similar to a slow strain rate isothermal forging process, as the powder has fully consolidated and is behaving as wrought material at high temperature.
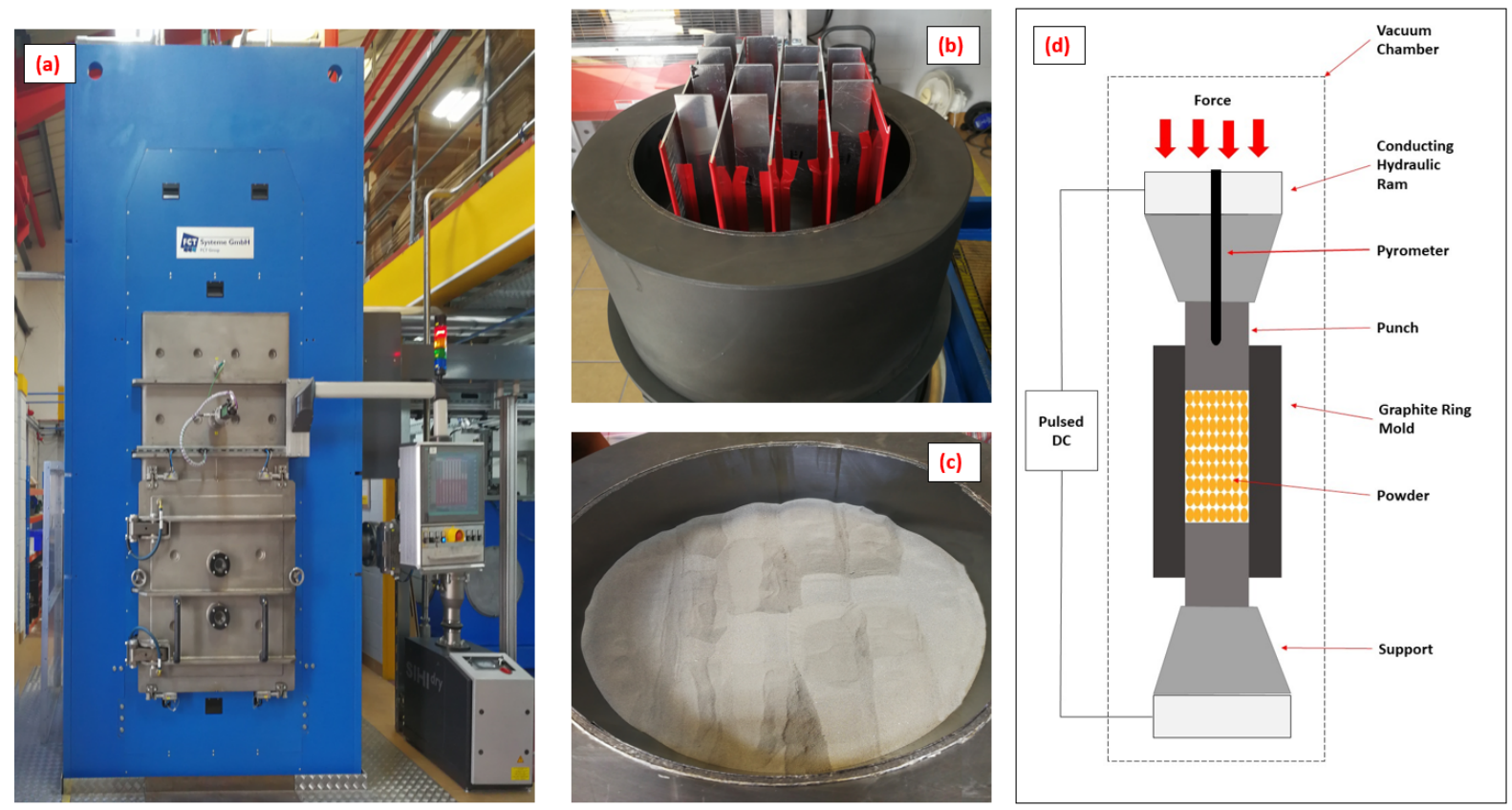

Figure 2. (a) Photograph of the FCT Systeme GmbH Spark Plasma Sintering Furnace type H-HP D 250 located at Kennametal Manufacturing (UK) Ltd. used to produce the FAST-DB disk, (b) Photograph of the graphite mould where the disk was processed with the dividers used to distribute the Ti-64 and Ti-6242 powders, (c) Photograph of the powder without the dividers in the $\mathbf{2 5 0} \mathrm{mm}$ diameter mould, (d) Schematic diagram of the FAST furnace arrangement. 


\subsection{Machining of the forging billets from the FAST-DB disk.}

The next step is to prepare the forging billets. First, it is necessary to remove the graphite paper adhered in the disk by grit blasting, see Figure 3 (a). Then, the preform billets were machined parallel to the bond, as shown in Figure 3 (c). A total of 5 off $22 \mathrm{~mm}$ diameter forging FAST-DB billets were machined, in addition, to a solely Ti-6242 forging billet. In Figure 3 (c) the distribution of the two titanium alloys in the forging billets is presented.

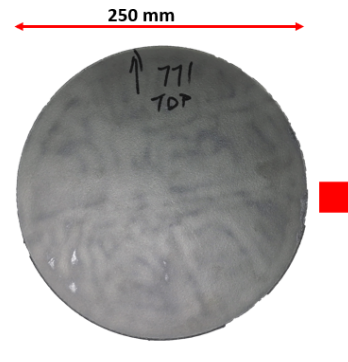

(a)

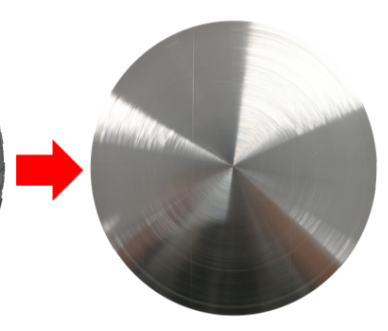

(b)

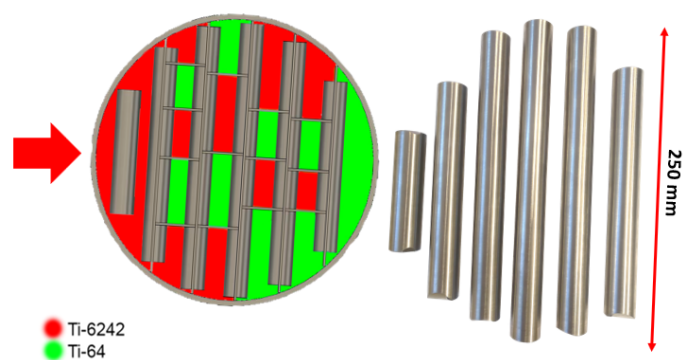

(c)

Figure 3. The steps of the pre-forge billet manufacture from the FAST-DB disk: (a) Photograph of the FAST-DB disk after removing the graphite paper by grit blasting, (b) Photograph of the FAST-DB disk after skimming the bottom surface and (c) Photograph of the machined forging billets with a CAD image showing the distribution of the two titanium alloys.

\subsection{Closed-die forging of the FAST-DB Ti-64/Ti-6242 billets}

The forging was conducted in collaboration with W.H. Tildesley, Wolverhampton, UK, one of the leading (and oldest) UK closed die forging specialists. A Massey 1.1 MSC drop hammer forge with foot pedal control and $11 \mathrm{~kJ}$ blow energy was used to forge the billets is shown in Figure 4 (a). The samples were heated in a gas furnace, shown in Figure 4 (b) at approximately $950^{\circ} \mathrm{C}$ for 10 minutes. The temperature of the billets was measured with two type $\mathrm{K}$ thermocouples inserted in a dummy sample with two holes. The temperature of the top die was $235^{\circ} \mathrm{C}$ and the bottom one was $320^{\circ} \mathrm{C}$.

The final near neat shape forged component profile was a legacy motorcycle rocker arm which had a good degree of complexity in order to understand and demonstrate the advantages of the FAST-DB and subsequent closed-die forging technology.

There were three main steps in the forging process. The first one was to remove the billet from the furnace with tongs and transfer it to the drop hammer bottom die. The second one was to forge the sample with 4 to 5 hammer blows and the final step was to crimp off the flash and quench the component in water. The component has a similar degree of complexity to a compressor blade and is of a similar size. The process required two specialist forgers doing the three steps, therefore, the time between each step varied for each sample. Consequently, three cameras were set up with the aim to know the time of each step during the forging process for all the samples. Figure 4 (c) shows some the The University of Sheffield authors with the W.H. Tildesley forging engineers from December 2018.

\subsection{Characterisation}

The samples were prepared following a standard metallographic procedure which included silicon carbide abrasive paper discs from P800 to P2500. The final polish was done with $0.06 \mu \mathrm{m}$ colloidal silica mixed with $10 \%$ concentration hydrogen peroxide. The microstructure was observed under cross-polarized light with a Reichert Jung Polyvar Met light microscope.

Heat tinting was used to differentiate the bond between the two alloys after sectioning the forged components. This technique consists in polishing the sample to mirror finish and oxidize the polished surface in a furnace at $540^{\circ} \mathrm{C}$ for $50 \mathrm{~min}$. The two titanium alloys have a different oxidation rates and oxide scales, for example Ti-64 has a brown colour as a result of the processing conditions, and therefore the exact location of bond line was easily distinguishable after quenching.
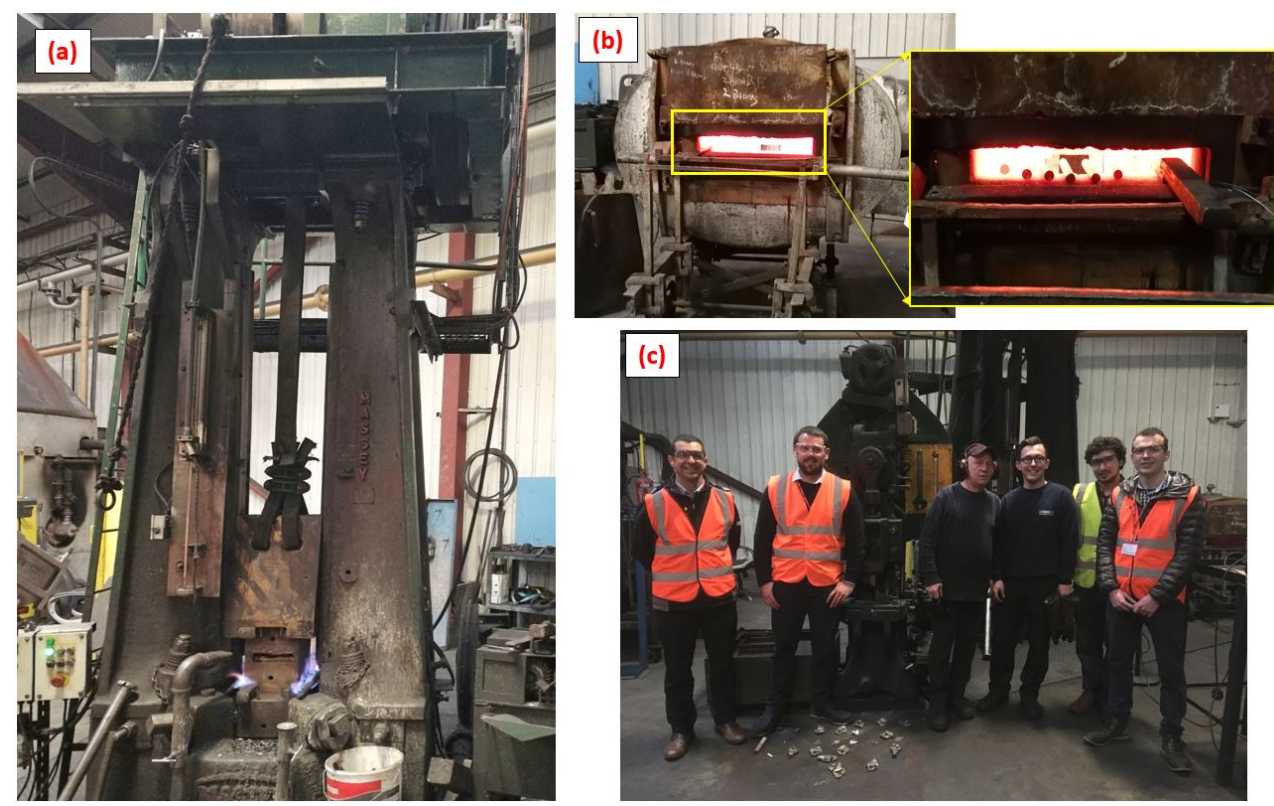

Figure 4. (a) Photograph of the drop hammer used to forge the FAST-DB billets, (b) Photograph of the gas furnace used to heat the pre-forged billets to the desired forging temperature, (c) Photograph from Dec 2018 of The University of Sheffield authors with the W.H.Tildesley forging engineers. 


\section{Results and Discussion}

A total of 13 rocker arms were forged from the original 6 forging billets. A video still image of a hot billet before and after the first hammer blow is shown in Figures $5(a)$ and $5(\mathrm{~b})$. It is important to note that the billet has a bond through middle of the billet, yet there is no negative indication of the bond during the closed-die forging step. The form of the final rocker arm shape is already visible in Figure 5(b), with three subsequent hammer blows to generate definition in the high strain sections. In fact, the forging engineers commented on how easy the FAST-DB billets were to forge compared to their experience with steel and even aluminium.

In Figure 5 (c) the final near net shape rocker arm after crimping and quenching is shown in Figure 5(c). As stated earlier, the different oxide colours make it easy to locate the evolution of the final bond line from top to bottom (red dotted line). The position of the bond was different for each of the 13 components, this was due to the way the initial forging billets were made, as discussed in section 2.3, and the human factor involved in the forging process (ie. locating the forging billet on the bottom die). Standard forging NDE dye penetrant inspection was carried out which further confirmed the structural integrity of the bond line post forging. Regardless of the position of the bond and the amount of bonds in the sample, no cracks were observed in any of the rocker arm components.
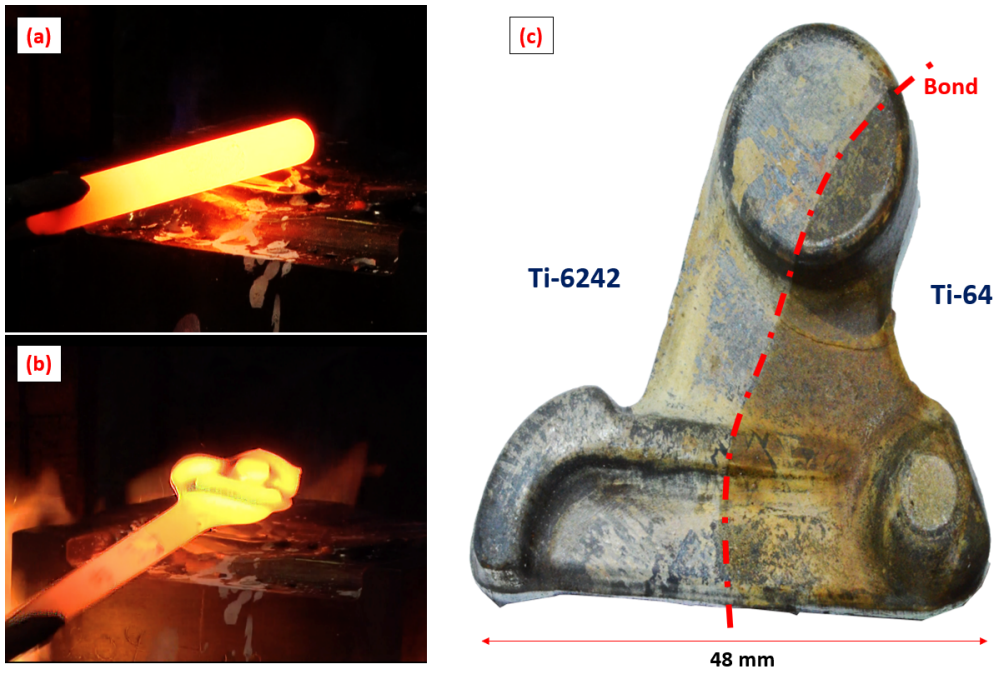

Figure 5. A video still of the FAST-DB forging billet (a) before the first drop hammer blow, and (b) fractions of a second after the first hammer blow. (c) A photograph of a final rocker arm near net shape component.

A select few of the rocker arm components have been sectioned, polished and then heat tinted to determine the position and the microstructure of the bond region, an example is shown in Figure 6 (a). The sectioned component shows that the bond line has experienced high levels of strain and severely plastically deformed, yet importantly the bond region is defect free.

The microstructure of the final components had a martensitic structure with parent beta grains, typical of super transus forging followed by water quenching, as shown in Figure 6 (b). Although it was planned to forge at subtransus temperatures (with respect to both titanium alloys), the gas furnace clearly went above $1100^{\circ} \mathrm{C}$ for short period, as shown in Figure 6(c).

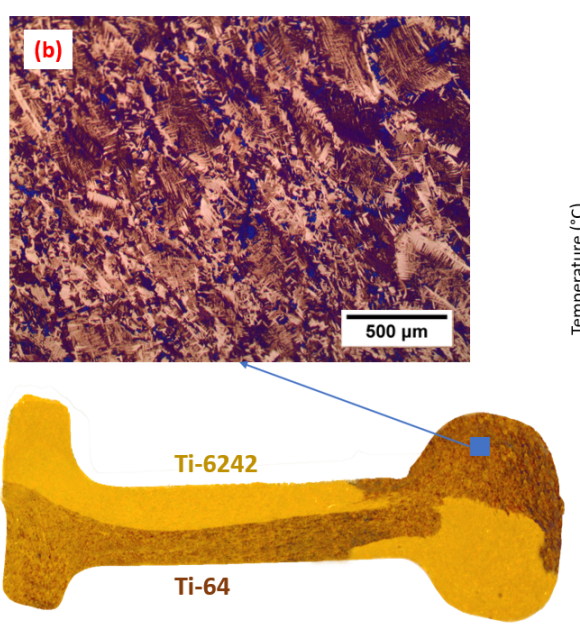

(a)

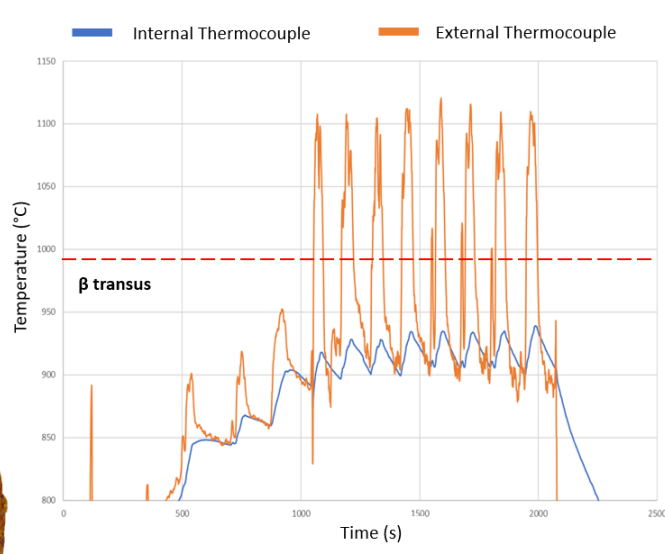

(c)

Figure 6. (a) Macrograph of the cross section from a forged rocker arm between Ti-64 and Ti-6242. (b) A light micrograph from the forged rocker arm region inside the blue box in (a). (c) Graph with the thermocouples measurements taken from the furnace prior the forging process.

\section{Conclusions}

FAST-forge, a two-step hybrid solid-state processing route, has successfully been demonstrated to convert two dissimilar alloy powders into one complex near net shape component. In step 1, Ti-64 and Ti-6242 spherical powders were fully consolidated into a disk with bonds using field assisted sintering technology (FAST-DB). In step 2, $22 \mathrm{~mm}$ diameter FAST-DB forging billets were closed-die forged using a traditional drop hammer press into rocker arm components. No flaws were found at any stage of the processing, even though the bond region was under severe plastic deformation during the forging stage.

The technology in this paper demonstrates that small-to-medium sized forgings can be produced in two simple steps from powder. Secondly, different titanium alloys with slightly different properties can be used in different regions of the part. FAST-forge of dissimilar alloys provides an opportunity for engineers and designers to better utilise alloys in specific locations. 


\section{Acknowledgements}

This research is funded under the EPSRC Rolls-Royce Strategic Partnership Grant and ICASE award EP/G0369550/1 through the Advanced Metallic Systems Doctoral Training Centre. The provision of materials and supporting information from Rolls-Royce plc. is gratefully acknowledged. The authors also acknowledge Peter Onions and Ashley Fieldhouse at W.H. Tildesley for the closed-die forging.

\section{Bibliography}

[1] M. Holmquist, V. Recina, and B. Pettersson, "Tensile and creep properties of diffusion bonded titanium alloy IMI 834 to gamma titanium aluminide IHI alloy 01A," Acta Mater., vol. 47, no. 6, pp. 1791-1799, 1999.

[2] X. F. Wang et al., "Diffusion bonding of $\gamma$-TiAl alloy to Ti-6Al-4V alloy under hot pressure," Trans. Nonferrous Met. Soc. China (English Ed., vol. 16 , no. 5, pp. 1059-1063, 2006.

[3] O. Guillon et al., "Field-assisted sintering technology/spark plasma sintering: Mechanisms, materials, and technology developments," Advanced Engineering Materials, vol. 16, no. 7. 2014.

[4] M. Suárez et al., "Challenges and Opportunities for Spark Plasma Sintering : A Key Technology for a New Generation of Materials," Sinter. Appl., pp. 319-342, 2013.

[5] D. He, Z. Fu, W. Wang, J. Zhang, Z. A. Munir, and P. Liu, "Temperature-gradient joining of Ti-6Al-4V alloys by pulsed electric current sintering," Mater. Sci. Eng. A, vol. 535, pp. 18-188, 2012.

[6] A. Miriyev, A. Stern, E. Tuval, S. Kalabukhov, Z. Hooper, and N. Frage, "Titanium to steel joining by spark plasma sintering (SPS) technology," J. Mater. Process. Technol., vol. 213, no. 2, pp. 161-166, 2013.

[7] N. Vicente, A. Fedrizzi, N. Bazzanella, F. Casari, F. Buccioti, and A. Molinari, "Microstructure of interface of SPS co-sintered and sinter bonded cp2-Ti and Co - 28Cr - 6Mo," Powder Metall., vol. 56, no. 2, pp. 143-148, 2013.

[8] K. Zhao, Y. Liu, L. Huang, B. Liu, and Y. He, "Diffusion bonding of Ti-45Al-7Nb-0.3W alloy by spark plasma sintering," J. Mater. Process. Technol., vol. 230 , pp. $272-279,2016$.

[9] G. Martin, D. Fabrègue, F. Mercier, J. A. Chafino-Aixa, R. Dendievel, and J. J. Blandin, "Coupling electron beam melting and spark plasma sintering: A new processing route for achieving titanium architectured microstructures," Scr. Mater., vol. 122, pp. 5-9, 2016.

[10] J. J. Pope, E. L. Calvert, N. S. Weston, and M. Jackson, "FAST-DB: A novel solid-state approach for diffusion bonding dissimilar titanium alloy powders for next generation critica components," J. Mater. Process. Technol., vol. 269, no. February, pp. 200-207, 2019.

[11] N. S. Weston and M. Jackson, "FAST-forge - A new cost-effective hybrid processing route for consolidating titanium powder into near net shape forged components," J. Mater. Process. Technol., vol. 243, pp. 335-346, 2017.

[12] E. Calvert, B. Wynne, N. Weston, A. Tudball, and M. Jackson, "Thermomechanical processing of a high strength metastable beta titanium alloy powder, consolidated using the low-cost FAST-forge process," J. Mater. Process. Technol., vol. 254, no. April 2017, pp. 158-170, 2018. 